\title{
ULTRASOUND-ASSISTED EXTRACTION AND CHARACTERIZATION OF POLYSACCHARIDE FROM MARYLAND TOBACCO LEAVES
}

\author{
SHAOHUA LIU ${ }^{1}$, PEIXIN HE, ZHAOFU TIAN ${ }^{1}$, XIAOLAN LI' ${ }^{1}$ CHUNPING XU²* \\ ${ }^{\prime}$ Technical center of China Tobacco Guangxi Industrial Co. Ltd., Nanning 530001, China \\ ${ }^{2}$ College of Food and Biological Engineering, Zhengzhou University of Light Industry, Henan 450002, China
}

\begin{abstract}
Ultrasound-assisted extraction (UAE) of polysaccharide from Maryland tobacco leaves was studied by response surface methodology. Furthermore, the crude polysaccharide was purified and two components (Fr-I and Fr-II) were obtained. FT-IR spectral analysis of the purified polysaccharide revealed prominent characteristic groups. The monosaccharide composition analysis by gas chromatography-mass spectrometry (GC/MS) indicated the main composition between Fr-I and Fr-II was different. Furthermore, thermo gravimetric analysis (TGA) indicated the degradation temperature (Td) of the Fr-I ( $\left.241^{\circ} \mathrm{C}\right)$ was higher than those of Fr-II $\left(216^{\circ} \mathrm{C}\right)$. Detected by the pyrolysis gas chromatography-mass spectrometry (py-GC/MS), it was found that the main kinds of pyrolysis products from both Fr-I and Fr-II were similar. Finally, On the basis of hydroxyl and DPPH radical scavenging assay, Fr-II has stronger antioxidant activities than Fr-I. The thermal behavior and antioxidant activity might be attributed to the configuration of the chemical compositions.
\end{abstract}

Keywords: antioxidant activity, extraction, optimization, Maryland tobacco leaves, polysaccharide

\section{INTRODUCTION}

Pectin, also known as pectic polysaccharide, is a major component of primary cell walls of land plants, and has been extensively investigated using chemical compositional analysis and enzymatic degradation ${ }^{1}$. The complicated structure of pectin suggests that it has multiple functions in plant growth and development ${ }^{2}$. Pectic polysaccharide extracted from higher plants has been widely used in food, cosmetic and pharmaceutical industries.

To the best of our knowledge, although the structural and bioactivities of pectic polysaccharide for several plant species are known, polysaccharide from tobacco leaves has been little investigated ${ }^{3,4}$.

Ultrasonic treatment is very promising to obtain bioactive polysaccharide from many plant materials with significant extraction efficiency in recent years ${ }^{5,6}$. The great extraction efficiency by ultrasonic treatment is mainly due to its mechanical effects, which promote targeted compounds to leave from the sample matrix into the solvent without changes on structural and molecular properties of plant materials ${ }^{7}$.

Maryland tobacco is one of light air-cured type tobacco, mainly used as a raw material of blended cigarettes. Its leaves is thin and light, extremely fluffy, loose but not rough in organizational structure, low nicotine with good burning properties and neutral aroma. The purpose of this study was to optimize the extraction conditions to simultaneously obtain the pectic polysaccharide from Maryland tobacco leaves using response surface methodology. Upon separation, two polysaccharide fractions were purified by Sepharose CL-6B chromatogram. Gas chromatography/mass spectrometry (GC/MS) and infrared spectrophotometry were applied to identify the chemical composition and structures. Thermal gravimetric analysis (TGA) confirmed the polysaccharides thermal stability. The pyrolysis gas chromatography-mass spectrometry (PyGC/MS) was used to detect quantitatively pyrolysis products. Finally, the comparative evaluation of the antioxidant capacities of leaf polysaccharide was also conducted.

\section{EXPERIMENTAL}

\section{Materials and reagents}

The Maryland tobacco was kindly provided from the R\&D center of Shanghai Tobacco (Group) Co., Ltd. (Shanghai, China). A voucher specimen (Md609) is deposited at our laboratory. The tobacco leaves was dried at $45{ }^{\circ} \mathrm{C}$ and ground to pass through a 40-mesh sieve prior to experiments. The standard monosaccharides were obtained from Sigma-Aldrich (St. Louis, MO), whilst Sepharose CL-6B was from the Sigma Chemical Co. (St Louis, MO). All other chemicals used were of analytical grade.

Extraction of polysaccharide from tobacco

The process of polysaccharides extraction from powder of the tobacco leaves by ultrasonic treatment was performed in an ultrasonic cell disintegrator (JY92-II, Ningbo Scientz Biotechnology Co., LTD, Lingbo, Zhejiang Province, China). The procedure of UAE was developed by ReboredoRodríguez et al. with some modifications ${ }^{8}$. One gram of the tobacco leaves (PTL) powder was extracted with distilled water in a cylindrical probe $(6 \mathrm{~mm}$ diameter). The extractions were carried out referring to conditions in Table 1. Debris fragments of polysaccharide extracts were removed by centrifugation. The solution of polysaccharide was concentrated with a rotary evaporator and precipitated with four volumes of absolute ethanol for $48 \mathrm{~h}$ at $4{ }^{\circ} \mathrm{C}$. The precipitate that formed was collected by centrifugation at $10000 \mathrm{rpm}$ and repeatedly washed sequentially with smaller amounts of ethanol, acetone, and ether, then deproteinized using Sevag reagent (1:4 n-butanol/chloroform, v/v). The aqueous phase was dialyzed against deionized water and lyophilized to obtain the crude polysaccharide (CPD). The extraction yields, subject of this study, were calculated as follows:

Table 1. Experimental range and levels of the independent process variables according the Box-Behnken experiment design. ${ }^{a}$

\begin{tabular}{|c|c|c|c|c|}
\hline Level & $\begin{array}{c}\text { Power (A) } \\
\text { W }\end{array}$ & $\begin{array}{c}\text { Time (B) } \\
\min \end{array}$ & $\begin{array}{c}\text { Ratio of } \\
\text { Solvent to Solid } \\
(\mathrm{C})\end{array}$ & $\begin{array}{c}\text { Temperature } \\
(\mathrm{D}) \\
{ }^{\circ} \mathrm{C}\end{array}$ \\
\hline 1 & 400 & 4 & 30 & 50 \\
\hline 2 & 500 & 6 & 35 & 60 \\
\hline 3 & 600 & 8 & 40 & 70 \\
\hline
\end{tabular}

aSymbols A, B, C, and D represent factors of extraction. Symbols 1, 2, and 3 represent concentration levels of each factor.

Extraction yields $(\%, \mathrm{w} / \mathrm{w})=\mathrm{W}_{\mathrm{CPD}} / \mathrm{W}_{\mathrm{PTL}} \times 100$

where $\mathrm{W}_{\mathrm{CPD}}$ was defined as mass of $\mathrm{CPD}$ whereas $\mathrm{W}_{\text {PTL }}$ was defined as mass of PTL used.

\section{Optimization of polysaccharide extraction}

Response surface methodology (RSM) was used for optimizing ultrasonic extraction conditions in the extraction of polysaccharides from Maryland tobacco leaves. As seen from Table 1, the extraction experiment was carried out with 4 factors and 3 levels, namely ultrasonic power $(400,500,600 \mathrm{~W})$, extraction time $(4,6,8 \mathrm{~min})$, ratio of water to raw material $(30,35,40)$ and extraction temperature $\left(50,60,70^{\circ} \mathrm{C}\right)$. The range of each factor level was based on the results of preliminary experiments. The experiments were arranged according to Box-Behnken experiment design. Response surface analysis was applied to determine the effect of casual factors on the yield of polysaccharides 
from Maryland tobacco leaves. The extraction yield (\%) of polysaccharide was the dependent variable. The polysaccharide obtained from the above 29 tests was operated following the method in the section of extraction of polysaccharide from tobacco.

\section{Polysaccharides Purification}

The polysaccharide was re-dissolved in $0.2 \mathrm{M} \mathrm{NaCl}$ buffer, and applied to a Sepharose CL-6B column $(2.4 \mathrm{~cm} \times 100 \mathrm{~cm})$ and eluted with the same buffer at a flow rate of $0.6 \mathrm{~mL} / \mathrm{min}$. Fractions $(5.0 \mathrm{~mL} /$ tube $)$ were collected by a fraction collector. The total carbohydrate content in the polysaccharide was determined by the phenol sulfuric acid method, using glucose as standard ${ }^{9}$ The peaks with the highest polysaccharide content were collected, dialyzed and then freeze-dried for further analysis.

\section{Monosaccharide composition analysis}

For the identification and quantification of monosaccharide, polysaccharide fraction ( $5 \mathrm{mg}$ ) was hydrolyzed with $2 \mathrm{~mL}$ of $2 \mathrm{M}$ trifluoroacetic acid (TFA) at $110{ }^{\circ} \mathrm{C}$ for $2 \mathrm{~h}$. The hydrolyzate was repeatedly co-concentrated with methanol, reduced with $\mathrm{NaBH}_{4}$ for $30 \mathrm{~min}$ at $20^{\circ} \mathrm{C}$ and acetylated with acetic anhydride and pyridine at $100{ }^{\circ} \mathrm{C}$ for $20 \mathrm{~min}$. The internal standard sugars were prepared and subjected to GC/MS analysis separately in the same way. The alditol acetates of polysaccharide fraction were analyzed by GC/MS (Varian Co., Model: Star 3600 CX, Lexington, MA, USA) fitted with a fused silica capillary column (Na form, $300 \mathrm{~mm} \times 0.25 \mathrm{~mm}$, Supelco Inc., Bellefonte, PA, USA) and a flame ionization detector.

\section{Fourier transform-infrared (FT-IR) spectroscopy}

FT-IR Spectroscopy (Bruker Tensor 27) was analyzed using the $\mathrm{KBr}$ disc for detecting functional groups. The purified polysaccharide fractions (1 $\mathrm{mg}$ ) were ground with $300 \mathrm{mg} \mathrm{KBr}$ powder and then pressed into pellets for transform IR spectral measurement on a Mattson Instrument from 550 to 4,000 $\mathrm{cm}^{-1}$. Spectra were corrected for wave number dependent signal-detection efficiency of the setup using the white light spectrum of a temperaturecalibrated tungsten band lamp.

\section{Thermo gravimetric analysis and pyrolysis GC/MS analysis}

Thermogravimetric analysis of the polysaccharide was done using TA Q5000IR TGA apparatus using $15 \mathrm{mg}$ polysaccharide fraction of the test material. The TGA curve plots the TGA signal, converted to percent weight change on the $Y$-axis against the reference material temperature on the $X$-axis. As for pyrolysis GC/MS analysis, samples $(0.1$ to $1 \mathrm{mg})$ were pyrolyzed in a quartz holder with a heated-filament pyrolyzer (Pyroprobe 1000) at $600{ }^{\circ} \mathrm{C}$ for $10 \mathrm{~s}$. The pyrolyzer was connected to a HP 6890 GC equipped with a HP 5973 quadrupole MSD analyzer, which in turn was coupled to an ion trap detector (Magnum; Finnigan). The GC column was a DB-5 fused silica capillary column $(30 \times 0.25 \mathrm{~mm}$ i.d. $\times 0.25 \mu \mathrm{m}$ d.f., J and W Scientific) for the separation. The GC oven was programmed to operate from 50 to $280{ }^{\circ} \mathrm{C}$ at $5{ }^{\circ} \mathrm{C} / \mathrm{min}$. The injector was at $250{ }^{\circ} \mathrm{C}$ in the split mode $(1 / 50$ split ratio). One microliter of product sample was injected onto the column and the components eluting from the column were analyzed using MS. Mass spectra were recorded under electron impact at $70 \mathrm{eV}$ from 30 to $550 \mathrm{~m} / \mathrm{Z}$ (1 scan per s). Compound-identification was done by comparing the standard mass spectra with in NIST02 library and other references ${ }^{10}$

\section{Antioxidant activity assays}

For the evaluation of antioxidant activity of polysaccharide extracted from tobacco leaves, DPPH Radical scavenging activity and $\mathrm{OH}$ radical scavenging activity were determined according to the methods of Eloff, et al. ${ }^{11}$ and Wang et al. ${ }^{12}$, respectively. In both assays the polysaccharide samples were predissolved in water and tested at various concentrations in parallel with vitamin $\mathrm{C}(\mathrm{Vc})$ as an antioxidant reference (positive control).

\section{Statistical analysis}

Data were expressed as means of triplicate experiments. The statistical significance was determined by Student's t-test. Design Expert (Stat-Ease Inc'Minneapolis'USA; version 8.05b) was used for the experimental designs and statistical analysis of the experimental data. Probability values $<0.05$ and $<0.01$ were regarded as statistically significant and highly significant, respectively.

\section{RESULTS AND DISCUSSION}

Optimization of extraction conditions by response surface methodology
Based on the preliminary single-factor experiment results, the response surface methodology was used to optimise the process of ultrasound-assisted extraction and investigate the relationships between variables of extraction factors. The experimental conditions for each project were listed in Table 2, and experimental results were also included in the last column of this table.

Table 2. Central composite design matrix and the responses of the dependent variables on polysaccharide extraction*.

\begin{tabular}{|c|c|c|c|c|c|}
\hline Run & $\begin{array}{c}\text { Power } \\
\text { (A) } \\
\text { W }\end{array}$ & $\begin{array}{l}\text { Time } \\
\text { (B) } \\
\text { min }\end{array}$ & $\begin{array}{l}\text { Ratio of } \\
\text { Solvent } \\
\text { to Solid } \\
\text { (C) }\end{array}$ & $\begin{array}{l}\text { Temperature } \\
\text { (D) }{ }^{\circ} \mathrm{C}\end{array}$ & $\begin{array}{l}\text { Extraction } \\
\text { yield }\end{array}$ \\
\hline 1 & 500 & 4 & 40 & 60 & $1.82 \pm 0.05$ \\
\hline 2 & 400 & 6 & 30 & 60 & $1.54 \pm 0.07$ \\
\hline 3 & 400 & 6 & 35 & 70 & $1.65 \pm 0.01$ \\
\hline 4 & 500 & 6 & 30 & 70 & $1.94 \pm 0.07$ \\
\hline 5 & 600 & 6 & 35 & 50 & $1.8 \pm 0.10$ \\
\hline 6 & 400 & 8 & 35 & 60 & $1.74 \pm 0.03$ \\
\hline 7 & 600 & 6 & 35 & 70 & $1.76 \pm 0.02$ \\
\hline 8 & 400 & 4 & 35 & 60 & $1.45 \pm 0.01$ \\
\hline 9 & 400 & 6 & 40 & 60 & $1.53 \pm 0.09$ \\
\hline 10 & 500 & 4 & 35 & 70 & $1.87 \pm 0.13$ \\
\hline 11 & 500 & 6 & 30 & 50 & $1.95 \pm 0.05$ \\
\hline 12 & 500 & 4 & 35 & 50 & $1.85 \pm 0.11$ \\
\hline 13 & 500 & 6 & 35 & 60 & $1.96 \pm 0.17$ \\
\hline 14 & 500 & 8 & 35 & 50 & $2.02 \pm 0.12$ \\
\hline 15 & 500 & 6 & 35 & 60 & $1.82 \pm 0.15$ \\
\hline 16 & 500 & 6 & 35 & 60 & $1.84 \pm 0.18$ \\
\hline 17 & 500 & 8 & 40 & 60 & $1.98 \pm 0.06$ \\
\hline 18 & 600 & 4 & 35 & 60 & $1.89 \pm 0.02$ \\
\hline 19 & 500 & 8 & 30 & 60 & $2.01 \pm 0.04$ \\
\hline 20 & 500 & 6 & 40 & 70 & $1.91 \pm 0.08$ \\
\hline 21 & 600 & 6 & 30 & 60 & $1.76 \pm 0.08$ \\
\hline 22 & 500 & 4 & 30 & 60 & $1.85 \pm 0.03$ \\
\hline 23 & 500 & 6 & 35 & 60 & $1.92 \pm 0.16$ \\
\hline 24 & 600 & 8 & 35 & 60 & $1.56 \pm 0.04$ \\
\hline 25 & 500 & 6 & 35 & 60 & $1.94 \pm 0.09$ \\
\hline 26 & 600 & 6 & 40 & 60 & $1.78 \pm 0.10$ \\
\hline 27 & 400 & 6 & 35 & 50 & $1.58 \pm 0.09$ \\
\hline 28 & 500 & 8 & 35 & 70 & $2.01 \pm 0.14$ \\
\hline 29 & 500 & 6 & 40 & 50 & $1.92 \pm 0.06$ \\
\hline
\end{tabular}

*The arrangements of column A, B C and D were decided by Box-Behnken design for 4 (factor) $\times 29$ (run number); every row of run number represents one experimental triplicate.

RSM is an effect method widely applied to optimization, being used for investigating effects of independent variables and their interaction terms to response values and give precise description about the relationships between the variables. According to the response surface methodology ${ }^{13}$, for the four factors varied five levels, this design was up of a full 29 factorial design as showed in Table 2. The experimental results were included in the last two columns of the table. Regression analysis on the experimental data, the following second order polynomial equation was shown to explain the polysaccharide production:

$\mathrm{Y}=-6.23+0.03 \mathrm{~A}+0.41 \mathrm{~B}-0.01 \mathrm{C}-0.03 \mathrm{D}-7.75 \mathrm{AB}+1.50 \mathrm{AC}-2.75 \mathrm{AD}-6.38 \mathrm{BC}-$ $3.75 \mathrm{BD}-2.02 \mathrm{CD}-2.42 \mathrm{~A}^{2}+2.38 \mathrm{~B}^{2}+8.00 \mathrm{C}^{2}+3.58 \mathrm{D}^{2}$ 
Where, $Y$ represents the response variable and A, B, C and D represent the coded values of extraction power, extraction time, ratio of water to raw material and temperature, respectively. The regression equation was optimized by the Design Expert to get the optimum values. The results showed that the optimum ultrasonic extraction conditions for polysaccharides were as follows: extraction power $490 \mathrm{~W}$, extraction time of $8 \mathrm{~min}$, ratio of water to raw material of $30: 1(\mathrm{~mL} / \mathrm{g})$ and $50{ }^{\circ} \mathrm{C}$.

The analysis of variance (ANOVA) of the quadratic regression model demonstrated that the model was highly significant, as was evident from the F-test with a very low probability value $(p<0.005)$. The Model F-value of 15.1 implied that the model was significant. There was only a $<0.01 \%$ chance that the "Model F-Value" that was this large could occur because of noise. The regression coefficients and the corresponding $p$ values were also shown in Table 4. The $p$ values of each model, confirmed that the four coefficients (A, $\mathrm{B}, \mathrm{AB}, \mathrm{A}^{2}$ ) were all significant. Therefore, both power, $\mathrm{A}$ and extraction time, $\mathrm{B}$ were important factors in polysaccharide yield process. Three dimensional response surface plots (Fig. 2A) and 2D contour plots (Fig. 2B) graphically represent regression equations were generally used to demonstrate the relative effect of power and extraction time. The optimal values obtained from the contour plot were almost equal to the obtained results by optimizing regression equation $(\mathrm{Eq}(1))$.

In order to confirm the optimization results, the suggested extraction conditions were confirmed in triplicate. The maximum predicted value of polysaccharide yield obtained was $2.01 \%$ where corresponding experimental response was $2.12 \mathrm{~g} / \mathrm{L}$. The experimental and predicted values of polysaccharide yields show good agreement with one another. The yield in this study is higher than the yield $(1.79 \%)$ from Nicotiana tabacum $L$ in the previous report by Zhu and Tao $(1993)^{14}$.

Isolation, purification and analysis of carbohydrates

The polysaccharide was obtained from the Maryland tobacco leaves by the method of ethanol precipitation. In gel filtration chromatography of the culture filtrate on Sepharose CL-6B, two fractions (designated as Fr-I and Fr-II) of polysaccharide were coeluted as shown in Fig. 1. This is in agreement with the results reported by Zhu and Tao (1993) for leaves of Nicotiana tabacum $\mathrm{L}^{14}$. They examined that two fractions were obtained by SephadexG-75 chromatography. The detailed monosaccharide compositions of carbohydrate in the two polysaccharide fractions by the trifluoroacetic acid hydrolysis and GC-MS analysis method are illustrated in Table 3. The result indicated that Fr-I was mainly composed of D-glucose $(31.07 \%)$, mannose $(20.02$ $\%$ ), and rhamnose (13.00\%), while Fr-II was mainly composed of mannose $(34.02 \%)$, galactose $(20.06 \%)$, and ribose $(15.19 \%)$. Although no data are currently available concerning the polysaccharide from Maryland tobacco, one polysaccharide isolated from burley tobacco was reported to be composed of galactose, arabinose, glucuronic acid and rhamnose ${ }^{15}$. Galacturonic acid was found as the main carbohydrate in leaves of Nicotiana tabacum $\mathrm{L}^{14}$.

Table 3. Analysis of variance (ANOVA) for the fitted quadratic polynomial model for optimization of polysaccharide extraction.

\begin{tabular}{|c|c|c|c|c|c|}
\hline \multirow{2}{*}{ Source } & \multirow{2}{*}{ Sum of Squares } & \multirow{2}{*}{$\mathrm{df}$} & \multirow{2}{*}{ Mean Square } & \multirow{2}{*}{ F Value } & $p$-value \\
\hline & & & & & Prob $>F$ \\
\hline Model & 0.67 & 14 & 0.048 & 15.1 & $<0.0001$ \\
\hline A & 0.094 & 1 & 0.094 & 29.75 & $<0.0001$ \\
\hline B & 0.029 & 1 & 0.029 & 9.22 & 0.0089 \\
\hline $\mathrm{C}$ & 0.001008 & 1 & 0.001008 & 0.32 & 0.5803 \\
\hline $\mathrm{D}$ & 0.00003333 & 1 & 0.00003333 & 0.011 & 0.9195 \\
\hline $\mathrm{AB}$ & 0.096 & 1 & 0.096 & 30.53 & $<0.0001$ \\
\hline $\mathrm{AC}$ & 0.000225 & 1 & 0.000225 & 0.071 & 0.7931 \\
\hline $\mathrm{AD}$ & 0.003025 & 1 & 0.003025 & 0.96 & 0.3435 \\
\hline $\mathrm{BC}$ & 0 & 1 & 0 & 0 & 1 \\
\hline $\mathrm{BD}$ & 0.000225 & 1 & 0.000225 & 0.071 & 0.7931 \\
\hline $\mathrm{CD}$ & 0 & 1 & 0 & 0 & 1 \\
\hline $\mathrm{A}^{2}$ & 0.38 & 1 & 0.38 & 120.45 & $<0.0001$ \\
\hline $\mathrm{B}^{2}$ & 0.0005854 & 1 & 0.0005854 & 0.19 & 0.6728 \\
\hline $\mathrm{C}^{2}$ & 0.00002595 & 1 & 0.00002595 & 0.008244 & 0.9289 \\
\hline $\mathrm{D}^{2}$ & 0.00829 & 1 & 0.00829 & 2.63 & 0.1269 \\
\hline Residual & 0.044 & 14 & 0.003147 & & \\
\hline Pure Error & 0.016 & 4 & 0.00388 & & \\
\hline Cor Total & 0.71 & 28 & & & \\
\hline
\end{tabular}

\section{FT-IR spectroscopy}

FT-IR is an effective analytical instrument for characterizing covalent bonding information and detecting functional groups. Typical IR spectra for the two polysaccharide fractions were presented in Fig. 2. All samples exhibited a broad stretching intense characteristic peak at approximately the region of $3280 \mathrm{~cm}^{-1}$ for the carbohydrate ring, and a weak C-H band at around $2928 \mathrm{~cm}^{-1}$.
A characteristic absorption band appeared at $1589.0-1605.3 \mathrm{~cm}^{-1}$ was assigned to the stretching vibration of the carboxyl group $(\mathrm{C}=\mathrm{O})$ of the polysaccharide. The stretching vibration peaks of around 1032.5-1040.7 $\mathrm{cm}^{-1}$ suggested the presences of C-O-H link bond position ${ }^{16}$. The characteristic absorption at 890.3 $\mathrm{cm}^{-1}$ was found in the IR spectrum of Fr-I, indicated $\alpha$-configuration of the sugar units ${ }^{16}$, which is in agreement with the results reported by Zhu and Tao ${ }^{17}$. 


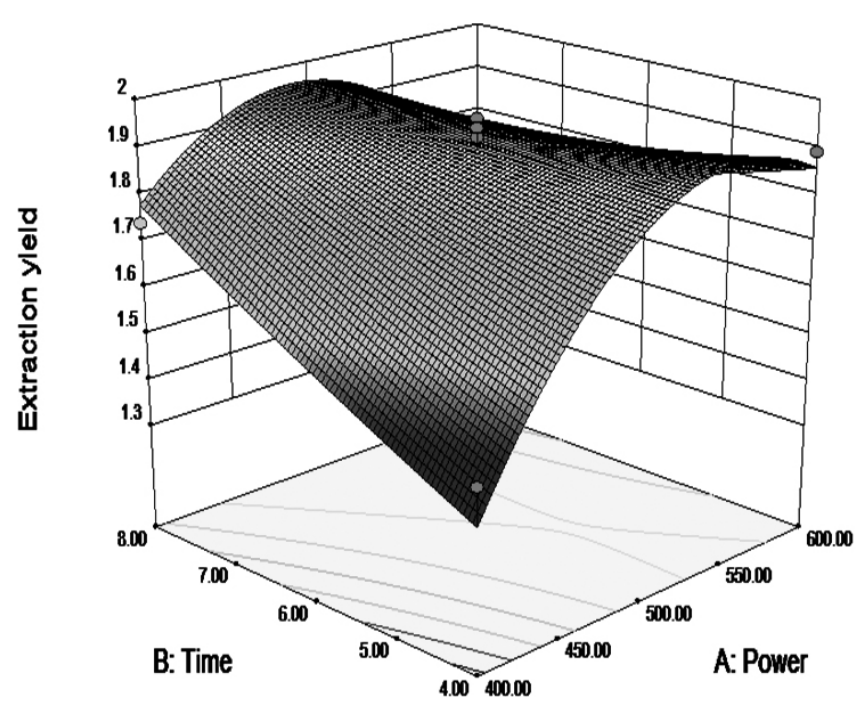

Fig 1. Response surfave plots showing the interaction between power and extraction time.

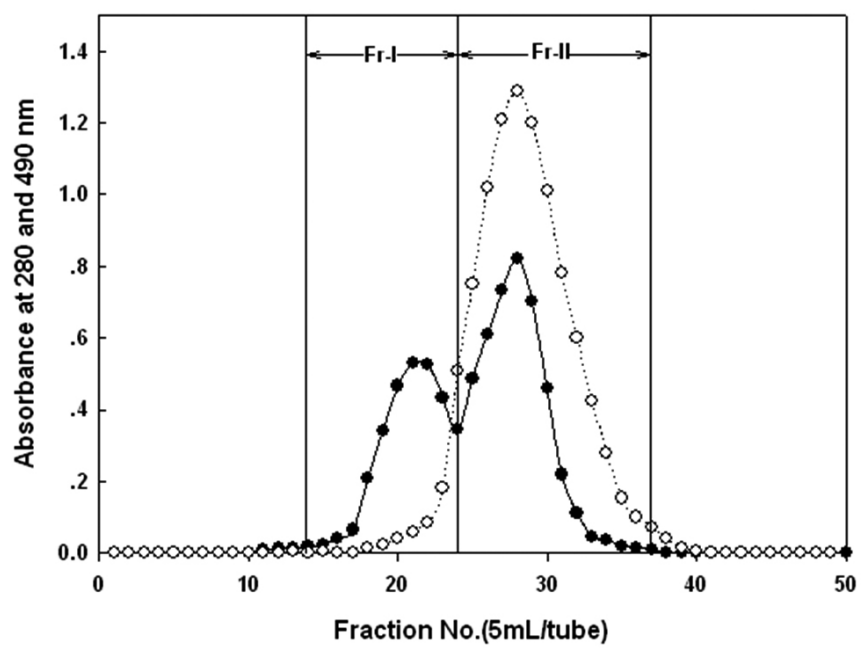

Fig. 2. Elution profiles of the pectic polysaccharide in Sepharose CL-6B chromatography. Elutes were analyzed by measuring the absorbance at $490 \mathrm{~nm}$ for carbohydrate.

\section{Thermal analysis of polysaccharide}

Thermogravimetric analysis involves measuring a sample's change in mass with variation of temperature and is a very useful technique for analyzing samples that either gain or lose mass during heating. The TGA analysis of purified polysaccharide fractions was carried out dynamically (weight loss versus temperature) and the experimental results are presented in Fig. 3 . According to the TGA curve of each fraction, the degradation temperature (Td) of Fr-I and Fr-II was determined as $241^{\circ} \mathrm{C}$, and $216^{\circ} \mathrm{C}$, respectively. This fact suggests that the material should not be submitted to the temperature of $\mathrm{Td}$ in order not to compromise the physical integrity of the material evaluated. Furthermore, the mass of each fraction was dramatically lost around $240{ }^{\circ} \mathrm{C}$ and continued gradually to decrease and the final residue was $20.97 \%$ for Fr-I and $36.54 \%$ for Fr-II. Through this analysis, it appears that the two fractions from Maryland tobacco leaves possess high thermal stability. Furthermore, the Fr-I and Fr-II have different behaviour to degradation, probably due to their different chemical compositions.

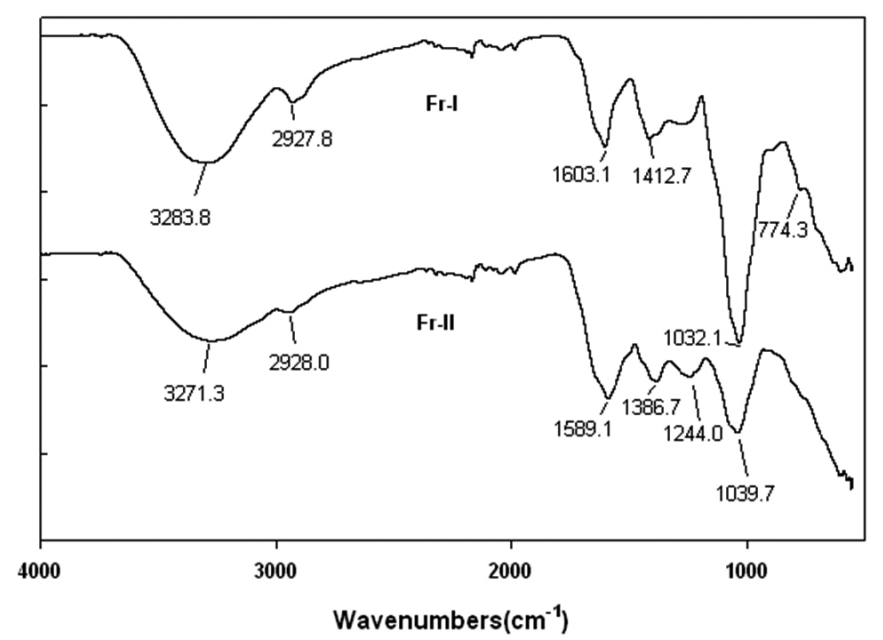

Fig. 3. The FT-IR spectra of the pectic polysaccharide fractions (Fr-I and Fr-II) from Maryland tobacco leaves.

The pyrolytic behavior is of great importance for the better understanding of the pyrolysis and thermochemical stability of polysaccharide. Py-GC/Ms is widely used techniques for characterizing the structural features on pyrolysates of polymeric materials, such as lignin and polysaccharide in plant. Py-GC/ MS is based on depolymerisation of the macromolecules by heat followed by identification of the fragments by mass spectrometry. Thus, the pyrolysis products are mainly depended on the compositions of substance ${ }^{18}$. Table 4 shows the thermal degradation products resulting from filament Py-GC-MS of Fr-I and Fr-II, respectively. As showed in Table 4, the main pyrolysis products of both Fr-I and Fr-II included ketones, acids, esters, phenolic, aomatic, aldehydes and others. However, the pyrolysis fragments derived from the Fr-II were significantly more abundant than those from Fr-I, particularly the amounts of heterocycle and aromatic compounds, whereas the highest percentage of pyrolysis fragments (i.e. 2,3-dimethyl-oxirane $\square$ 2,3-butanedione, furfural and 1,2-benzenediol) was detected in Fr-I. The results indicate that there is a considerable variation in chemical composition between Fr-I and Fr-II.

Table 4. Carbohydrate composition in the purified pectic polysaccharide fractions (Fr-I and Fr-II) extracted from the Maryland tobacco leaves.

\begin{tabular}{|c|c|c|}
\hline Carbohydrate composition (\%) & Fr-I & Fr-II \\
\hline D-deoxyribose & 3.46 & 2.31 \\
\hline D-arabinose & 11.79 & 7.86 \\
\hline L-rhamnose & 10.25 & 14.39 \\
\hline D-ribose & 13.56 & 11.21 \\
\hline D-(-) - lyxose & 2.48 & 0.00 \\
\hline D-xylose & 4.37 & 3.24 \\
\hline 2-Deoxy-D-Glucose & 0.00 & 3.27 \\
\hline D-(+) - tarot pyranose & 1.83 & 2.37 \\
\hline D-(+) - tarot furanosyl & 6.45 & 2.22 \\
\hline D-(+) - galactose & 18.20 & 10.32 \\
\hline D-glucose & 1.61 & 8.90 \\
\hline D-(+) - mannose & 24.26 & 15.79 \\
\hline D-allose & 1.74 & 5.55 \\
\hline maltose & 0.00 & 4.21 \\
\hline L - trehalose & 0.00 & 1.15 \\
\hline D-(+)-Cellobiose & 0.00 & 7.20 \\
\hline
\end{tabular}


Antioxidant properties analysis

In this experiment, the in vitro antioxidant capacities of two fractions from the Maryland tobacco leaves were evaluated using different biochemical methods including hydroxyl and DPPH radical scavenging assay. Hydroxyl radical can react with most biomacromolecules functioning in living cells and induce severe damage to the adjacent biomolecules ${ }^{12}$. The results of hydroxyl radical scavenging activities of two polysaccharide fractions are shown in Fig. 4A. The results showed that the hydroxyl radical scavenging activities enhanced corresponding to increase with the concentration. The ability of Fr-II was stronger than that of Fr-I at every concentration point and the $\mathrm{OH}$ radical scavenging rate at $4 \mathrm{mg} / \mathrm{mL}$ was $63.25 \%$. DPPH radical is a widely used method to evaluate the free radical scavenging ability of natural compounds ${ }^{19}$. In this experiment, scavenging rates of Fr-I and Fr-II on DPPH free radical were showed in Fig. 4B. The results showed that the polysaccharide increased the radical scavenging activity in a concentration dependant manner. The scavenging activities of Fr-II were stronger than those of Fr-I, and finally reached to $72.12 \%$ at the concentration of $2.0 \mathrm{mg} / \mathrm{mL}$.

Table 5. Pyrolysis products of the purified pectic polysaccharide fractions (Fr-I and Fr-II) extracted from the Maryland tobacco leaves.

\begin{tabular}{|c|c|c|c|c|c|}
\hline No. & $\begin{array}{c}\mathrm{Rt} \\
(\mathrm{min})\end{array}$ & Name & Qual & Fr-I (\%) & Fr-II (\%) \\
\hline 1 & 1.87 & 2,3-Dimethyl oxirane & 38 & 7.22 & - \\
\hline 2 & 2.01 & 1,3-Cyclopentadiene & 93 & - & 2.36 \\
\hline 3 & 2.05 & 1-Propanol & 9 & 1.64 & - \\
\hline 4 & 2.15 & 2,3-Butanedione & 27 & 4.13 & - \\
\hline 5 & 2.37 & Acetic acid & 91 & 7.16 & 5.02 \\
\hline 6 & 2.57 & Hydroxyacetone & 80 & 7.87 & - \\
\hline 7 & 2.82 & 2,3-Pentanedione & 37 & 0.82 & 0.32 \\
\hline 8 & 2.97 & 1-Propoxy-2-propanol & 12 & 2.43 & 0.3 \\
\hline 9 & 3.02 & 2,5-Dimethylfuran & 38 & - & 0.49 \\
\hline 10 & 3.39 & N-Methyl pyrrole & 90 & 0.65 & 0.83 \\
\hline 11 & 3.48 & 2-Methyl furan & 81 & 0.9 & 0.65 \\
\hline 12 & 3.52 & Pyridine & 93 & - & 0.69 \\
\hline 13 & 3.61 & Pyrrole & 83 & 1.22 & 2.16 \\
\hline 14 & 3.72 & 1,4-Diacetoxybutane & 23 & - & 0.37 \\
\hline 15 & 3.8 & Acethydrazide & 16 & 2.64 & 0.37 \\
\hline 16 & 4.05 & Methyl pyruvate & 49 & 1.72 & 0.61 \\
\hline 17 & 4.21 & Thiophene & 38 & 1.03 & 0.71 \\
\hline 18 & 4.27 & DL-Pipecolinic acid & 28 & 0.47 & - \\
\hline 19 & 4.53 & 3-Furaldehyde & 76 & 0.4 & 1.82 \\
\hline 20 & 4.67 & 2-Methyl pyridine & 92 & 0.42 & 2.51 \\
\hline 21 & 4.93 & Furfural & 95 & 3.35 & - \\
\hline 22 & 5.11 & 2-Ethyl-1H-pyrrole & 70 & 0.7 & 0.17 \\
\hline 23 & 5.44 & 2-Furanmethanol & 93 & 0.69 & - \\
\hline 24 & 5.58 & 3-Picoline & 96 & - & 0.8 \\
\hline 25 & 5.73 & 1,2-Diacetoxyethane & 45 & 2.55 & 0.75 \\
\hline 26 & 6.08 & 2-Cyclopentene-1,4-dione & 80 & 0.35 & 0.35 \\
\hline 27 & 6.18 & cis-4-Methylcyclohexanol & 37 & - & 0.09 \\
\hline 28 & 6.23 & Styrene & 96 & 0.24 & 0.41 \\
\hline 29 & 6.55 & Dicyclopropyl ketone & 50 & 0.13 & - \\
\hline 30 & 6.73 & 2-Acetylfuran & 83 & 0.23 & 0.25 \\
\hline 31 & 6.81 & 1,3,5-Trimethylpyrazole & 52 & 0.4 & 0.24 \\
\hline 32 & 6.86 & 2(5H)-Furanone & 52 & - & 0.5 \\
\hline 33 & 7.06 & 2,6-Dimethylpiperidine & 47 & - & 0.29 \\
\hline 34 & 7.16 & 1,2-Cyclopentanedione & 72 & 1.88 & 1.21 \\
\hline 35 & 7.3 & 2,4-Dimethyl pyridine & 90 & 0.15 & 0.35 \\
\hline 36 & 7.32 & 3,5-Dimethyl pyridine & 87 & - & 0.07 \\
\hline 37 & 7.5 & 5-Methyl-2(5H)-furanone & 81 & 0.17 & 2.56 \\
\hline
\end{tabular}




\begin{tabular}{|c|c|c|c|c|c|}
\hline 38 & 7.68 & 3,5-Dimethylcyclohexanol & 42 & - & 0.14 \\
\hline 39 & 7.81 & 5-Methyl-2(3H)-furanone & 43 & 0.19 & 0.9 \\
\hline 40 & 7.91 & 2-Hydroxypropyl acrylate & 22 & - & 0.58 \\
\hline 41 & 8.03 & Sorbic acid & 35 & 0.12 & - \\
\hline 42 & 8.04 & 5-Methyl-3-hexen-2-one & 11 & - & 0.19 \\
\hline 43 & 8.14 & 5-Methyl furfural & 95 & 1.24 & 0.44 \\
\hline 44 & 8.2 & 3-Methyl-2-cyclopenten-1-one & 89 & 0.47 & 0.5 \\
\hline 45 & 8.56 & 2-Hexanoylfuran & 50 & 0.38 & 0.7 \\
\hline 46 & 8.77 & Phenol & 93 & 0.82 & - \\
\hline 47 & 8.99 & 2,5-Dimethyl-2,4-hexadiene & 70 & 0.27 & - \\
\hline 48 & 9.12 & Bromofluoromethane & 38 & 0.88 & 0.21 \\
\hline 49 & 9.17 & 3-Methyl-2,4-imidazolidinedione & 53 & 0.33 & 0.26 \\
\hline 50 & 9.34 & 3-Butoxypropylamine & 37 & 0.3 & 0.54 \\
\hline 51 & 9.43 & 4-Methyl-cyclohexanol & 38 & - & 0.32 \\
\hline 52 & 9.6 & trans-2-Methyl-cyclohexanol & 53 & 0.49 & 0.26 \\
\hline 53 & 10.15 & 3-Methyl-1,2-cyclopentanedione & 97 & 1.34 & 1.78 \\
\hline 54 & 10.24 & 3,5,5-Trimethyl-2-cyclopenten-1-one & 50 & 0.07 & - \\
\hline 55 & 10.44 & 2-Methyl-5-(methylthio)-furan & 38 & 2.05 & 0.62 \\
\hline 56 & 10.77 & 1,3-Dimethyl-2-imidazolidinone & 50 & - & 0.21 \\
\hline 57 & 10.85 & 2-Methyl phenol & 96 & 1.05 & 0.18 \\
\hline 58 & 10.99 & 4,5-Dimethyl-1,3-dioxol-2-one & 35 & 0.36 & 0.3 \\
\hline 59 & 11.09 & Guanazine & 25 & - & 0.65 \\
\hline 60 & 11.27 & 1-Tridecyne & 22 & 0.16 & 1.17 \\
\hline 61 & 11.47 & 4-Methylphenol & 97 & 0.04 & 0.24 \\
\hline 62 & 12.18 & 1,2-Dimethyl cyclopropene & 66 & 0.15 & 0.16 \\
\hline 63 & 12.31 & 2,6-Dimethylphenol & 90 & 0.14 & 0.32 \\
\hline 64 & 12.56 & Maltol & 91 & 0.76 & 0.22 \\
\hline 65 & 12.74 & 3-Ethyl-2-hydroxy-2-cyclopenten-1-one & 50 & 0.52 & 0.25 \\
\hline 66 & 13.05 & 5-Hydroxy-2-methyl-4H-pyran-4-one & 38 & - & 0.14 \\
\hline 67 & 13.26 & 2(1H)-Pyridinone & 46 & - & 0.67 \\
\hline 68 & 13.4 & Ethyl-4-pyrazolecarboxylate & 58 & 0.3 & 0.77 \\
\hline 69 & 13.48 & 4-Pyridinol & 45 & - & 0.37 \\
\hline 70 & 13.53 & 2,4-Dimethyl phenol & 95 & 0.41 & 0.97 \\
\hline 71 & 13.98 & 2,3-Dihydroxybenzaldehyde & 55 & - & 0.25 \\
\hline 72 & 14.08 & 4-Ethyl phenol & 91 & 0.14 & 0.22 \\
\hline 73 & 14.39 & 3,5-Dimethyl phenol & 60 & 0.18 & 0.21 \\
\hline 74 & 14.47 & Benzoic Acid & 35 & - & 0.28 \\
\hline 75 & 14.55 & 6-Methyl-3-pyridinol & 58 & 0.07 & 6.10 \\
\hline 76 & 14.9 & Trimethylol propane & 38 & 0.21 & - \\
\hline 77 & 15.18 & Pentanoic acid heptyl ester & 37 & 1.16 & 0.37 \\
\hline 78 & 15.25 & Cycloheptanol & 14 & - & 0.11 \\
\hline 79 & 15.38 & 1,2-Benzenediol & 90 & 3.59 & 0.27 \\
\hline 80 & 16.92 & 4-Methyl-1,2-benzenediol & 90 & 0.09 & 0.31 \\
\hline 81 & 17.1 & 1-(2,5-Dihydroxyphenyl) ethanone & 87 & 0.18 & 1.36 \\
\hline 82 & 17.22 & 1-Indanone & 96 & 0.18 & 0.21 \\
\hline 83 & 17.4 & N-Butyl acetamide & 35 & 0.13 & 0.21 \\
\hline
\end{tabular}




\begin{tabular}{|c|c|c|c|c|c|}
\hline 84 & 17.56 & 1-Methyl naphthalene & 30 & - & 0.69 \\
\hline 85 & 17.62 & Indole & 93 & 0.44 & 1.44 \\
\hline 86 & 18.73 & 3,5-Dimethyl-4H-pyran-4-one & 46 & - & 0.17 \\
\hline 87 & 19.19 & L-Nicotine & 95 & - & 1.8 \\
\hline 88 & 19.45 & 2-Methyl-1,4-benzenediol & 95 & 0.27 & 5.83 \\
\hline 89 & 20.05 & 3-Methyl-1H-indole & 92 & 0.28 & - \\
\hline 90 & 20.53 & 1,6-Anhydro-.beta-D-glucopyranose (levoglucosan) & 59 & 1.46 & 0.75 \\
\hline 91 & 21.05 & Pyridine, 3-(3,4-dihydro-2H-pyrrol-5-yl)- & 70 & 1.05 & 0.94 \\
\hline 92 & 21.85 & Ethyl vanillin & 60 & 0.17 & 0.16 \\
\hline 93 & 22.44 & 2,4,6-Trimethyl benzonitrile & 95 & 0.05 & - \\
\hline 94 & 22.51 & 3-(1-Methyl-1H-pyrrol-2-yl)-pyridine & 95 & - & 0.24 \\
\hline 95 & 22.67 & 2,5-Dimethyl-1H-indole & 87 & 0.11 & 2.07 \\
\hline 96 & 23.68 & 2,3 '-Dipyridyl & 96 & 0.12 & 0.49 \\
\hline 97 & 24.37 & Dodecanoic acid & 87 & 0.14 & 0.21 \\
\hline 98 & 27.66 & 3-Phenoxy phenol & 47 & - & 2.3 \\
\hline 99 & 32.79 & n-Hexadecanoic acid & 96 & 0.08 & 0.26 \\
\hline 100 & 33.3 & Dodecamethyl pentasiloxane & 30 & 0.07 & 0.84 \\
\hline 101 & 38.36 & Butyl citrate & 0.05 & 0.1 \\
\hline
\end{tabular}

${ }^{\mathrm{a}} \mathrm{MQ} \%=$ match quality.

${ }^{b}$ not detected.

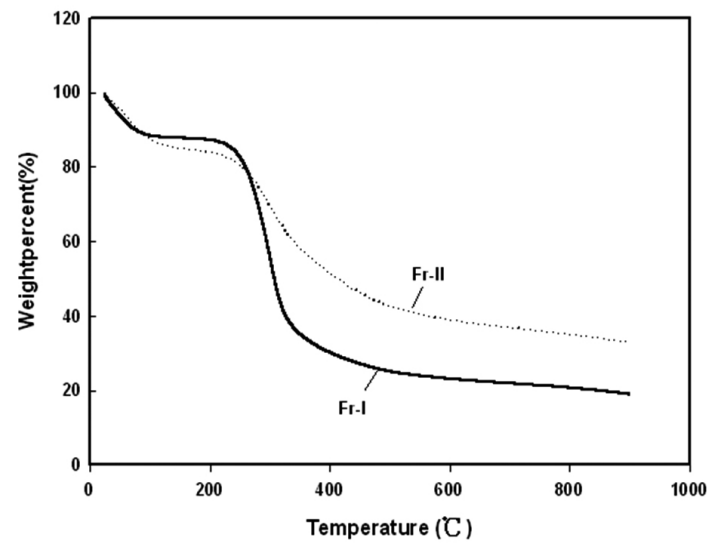

Fig. 4. TGA thermogram of pectic polysaccharide fractions (Fr-I and Fr-II) from Maryland tobacco leaves.
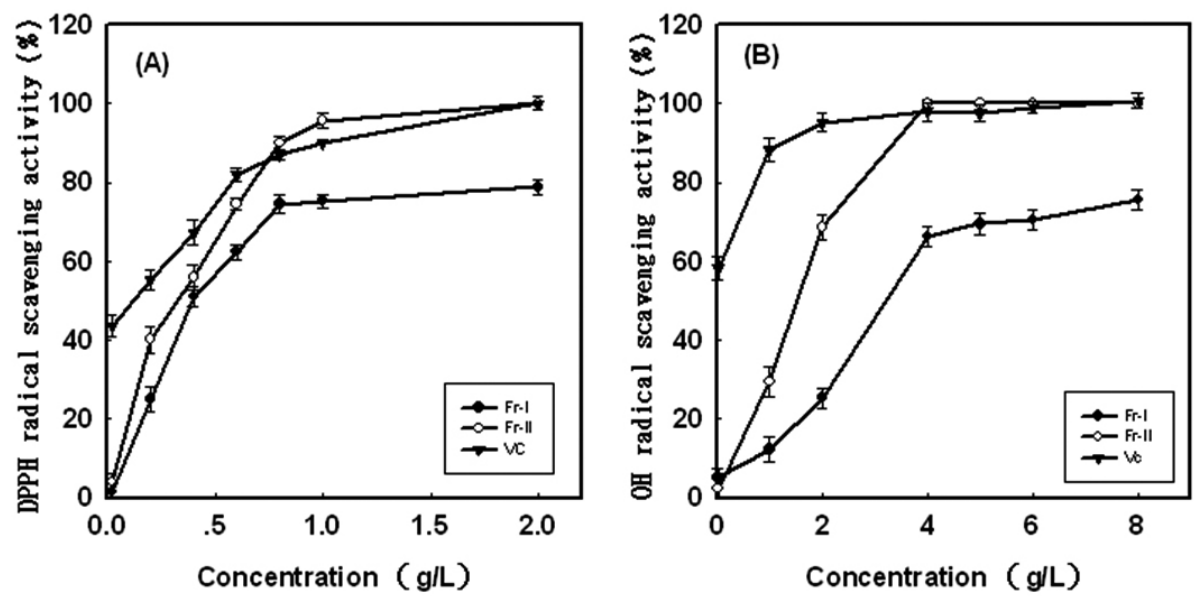

Fig. 5. Antioxidant activity of pectic polysaccharide fractions (Fr-I and Fr-II) from Maryland tobacco leaves. The results represent mean \pm S.D. $(n=3)$. OH (A) and ABTS (B) radical scavenging activity of polysaccharide. Vitamin C (q), Fr-I (•) and Fr-II (०). 
In this experiment, both polysaccharide fractions showed significant antioxidant effects. However, the Fr-II has stronger antioxidant activities than Fr-I, which probably attribute monosaccharide compositions. This is in accordance with the report by Wang et al. for the polysaccharide extract from green tea ${ }^{20}$. They suggested that the antioxidant abilities of the polysaccharide fractions of green tea were supposed to relate to the chemical compositions.

\section{CONCLUSIONS}

As a more practical method, the response surface methodology was employed to study the relationships between the extraction condition and effect on extraction yield. The factors of UAE on the yield of polysaccharide from Maryland tobacco leaves were studied by using response surface methodology. The results showed that an optimum yield of polysaccharide could be obtained when conditions were set as follows: ultrasonic power was of $490 \mathrm{~W}$, extraction time of $8 \mathrm{~min}$, ratio of water to raw material of $30: 1(\mathrm{~mL} / \mathrm{g})$ and $50{ }^{\circ} \mathrm{C}$. The crude polysaccharide was purified with Sepharose CL-6B column, and two components were obtained (Fr-I and Fr-II). The characterization of Fr-I and FrII was analysed with FT-IR spectroscopy, GC, TGA and Py-GC/MS analysis. Furthermore, both polysaccharide fractions showed strong antioxidant activity.

\section{REFERENCES}

1.- A. G. J. Voragen, G. Coenen, R.P. Verhoef and H. A. Schols. Struct Chem. 20,263 (2009)

2.- D. Mohnen Curr. Opin. Plant Biol. 11,266 (2008).

3.- Z. Ying, X. Han and J. Li, Food Chem., 127,1273 (2011).

4.- E. Nguema-Ona, J.P. Moore, A. Fagerström, J.U. Fangel, W.G.T. Willats, A. Hugo and M.A. Vivier, Carbohyd. Polym., 88,939 (2012).
5.- K. Zhong and Q. Wang, Carbohyd. Polym., 25,19 (2010).

6.- H.M. Chen, X. Fu and Z.G. Luo, Food Chem, 168,302 (2015)

7.- J. Chandrapala, C.M. Oliver, S. Kentish and M. Ashokkumar, Food Rev. Int., 29, 67(2013).

8.- P. Reboredo-Rodríguez, L. Rey-Salgueiro, J. Regueiro, C. GonzálezBarreiro, B. Cancho-Grande and J. Simal-Gándara. Food Chem., 8,347 (2014).

9.- M. Rasouli, A. Ostovar-Ravari, H. Shokri-Afra, Eur. Rev. Med. Pharmacol. Sci., 18, 2020 (2014)

10.- A. Pirasa, A. Rosa, B. Marongiu, S. Porcedda, D. Falconieri, M.A. Dessì, B. Ozcelik and U. Koca, Ind. Crop Prod. ,46,317 (2013).

11.- J.N. Eloff, D.R. Katerere and L.J. McGaw J Ethnopharmacol., 119,686 (2008).

12.- J.L. Wang, J. Zhang, B.T. Zhao, X.F. Wang, Y.Q. Wu and J. Yao, Carbohyd. Polym., 80,84 (2012).

13.- Y. Sun, Y. Li, M. Li, H. Tong, X. Yang and J. Liu, Carbohyd. Polym., 5,575 (2009).

14.- X. Zhu and L. Tao, Acta Tobacco Sinica.,1,8 (1993).

15.- H.E. Jr Wright, W.W. Burton and R.C. Jr. Berry, Phytochem., 1,125 (1962).

16.- B.G. Goo, G. Baek, D.J. Choi, Y.I. Park, A. Synytsya, R. Bleha, D.H. Seong, C.G. Lee and J.K. Park, Bioresource Technol., 129,343 (2013).

17.- N. Li, C. Yan, D. Hua and D. Zhang, Int. J. Biol. Macromol., 57,285 (2013).

18.- V. Becerra, J. Odermatt and M.Nopens, J. Anal. Appl. Pyrol. 103, 42 (2013).

19.- J. Xiao, J. Huo, H. Jiang and F. Yang, Int. J. Biol. Macromol.,49,1143 (2011).

20.- Y. Wang, F. Mao and X. Wei, Int. J. Biol. Macromol., 88,146 (2012). 